\title{
Rupture of the Gravid Uterus: Experience of the Maternity Hospital, Kuwait
}

\author{
M.H. Al Salem ${ }^{a}$ M. Makhseed ${ }^{a}$ b M.A. Ahmed ${ }^{b}$ M. Gupta ${ }^{a}$ \\ aMaternity Hospital, bDepartment of Obstetrics and Gynecology, Faculty of Medicine, \\ Kuwait University, Kuwait
}

\section{Key Words}

Uterine rupture Predisposing factors .

Outcome $\cdot$ Management

\begin{abstract}
Objective: To review the cases of ruptured uteri at the Maternity Hospital, Kuwait, over a period of 11 years, and to analyze the predisposing factors, maternal and fetal outcome and modes of management. Method: This is a retrospective study of 91 cases of uterine rupture out of 168,486 deliveries at the Maternity Hospital, Kuwait, between January 1981 and December 1993. Result: The incidence of uterine rupture was 1 in 1,851. A previous uterine scar was present in 51 (56\%) cases. The percentage of cases with instrumental delivery, malpresentation, history of previous cesarean section, use of oxytocics, higher age of the mother and parity of 5 or
\end{abstract}

\begin{tabular}{ll}
\hline KARGER & ( ) 2000 S. Karger AG, Basel \\
1011-7571/00/0092-0097\$17.50/0 \\
$\begin{array}{l}\text { Fax +4161306 1234 } \\
\begin{array}{l}\text { E-Mail karger@karger.ch } \\
\text { www.karger.com }\end{array}\end{array}$ & $\begin{array}{l}\text { Accessible online at: } \\
\text { www.karger.com/journals/mpp }\end{array}$
\end{tabular}

more was significantly higher in mothers with uterine rupture than mothers without uterine rupture. The percentage of cases with parity of 5 or more and those using oxytocics was significantly higher in the unscarred uterus group than scarred uterus group. Anterior lower segment was the most common site of rupture. The percentage of cases with simple repair of the uterus was higher in patients with the unscarred uterus than scarred uterus. Total hysterectomy was more common in patients with previously unscarred uterus. The perinatal and maternal mortality was 25.5 and $3.3 \%$, respectively. Conclusion: The incidence of uterine rupture in this study is comparable to that in developed countries. Previous uterine scar, use of oxytocics, grand multiparity, instrumental delivery and malpresentation are associated with the rupture of the gravid uterus.

Copyright $\odot 2000$ S. Karger AG, Basel

Dr. Ma'asoumah Makhseed

Department of Obstetrics and Gynecology, Faculty of Medicine Kuwait University, PO Box 24923

13110 Safat (Kuwait)

Fax +9655338906 


\section{Introduction}

Uterine rupture during pregnancy is an obstetric emergency that has a high morbidity and mortality to both the mother and the fetus, making it one of the catastrophes of obstetric practice. It is a more serious threat to life in rural areas of developing countries, where obstetric care is often limited and transportation is poor. In advanced countries, with a decrease in multiparity and increased rate of cesarean section, there has been a decrease in the incidence of uterine rupture $[1,2]$. However it should be kept in mind that in patients who previously had operations like cesarean section, hysterotomy, and myomectomy, the risk of uterine rupture is 8-30 times the risk in patients with no previous scar [3, 4]. The reported incidence of uterine rupture varies widely, ranging from 1:97 [5] to $1: 6,637[6]$.

The classical signs of uterine rupture may be present in only a third of the patients [1], which makes the condition difficult to diagnose. A greater awareness of the condition, good obstetric assessment, early diagnosis and prompt treatment by experienced personnel are important features in reducing morbidity and mortality.

This retrospective study was carried out in the Maternity Hospital, Kuwait, to determine the predisposing factors, modes of management, maternal and fetal outcome of uterine rupture, and to identify the size of the problem.

\section{Patients and Methods}

In this study of 91 cases of uterine rupture ( 88 singleton and 3 twin pregnancies) at the Maternity Hospital, Kuwait involving 168,486 deliveries, between January 1981 and December 1993 (data for the years 1990 and 1991 are missing due to the Gulf crisis). The Maternity Hospital is the main obstetric and gyneco- logical hospital in Kuwait with an average of 15,317 deliveries per year. It is also the main center which accepts referrals of high risk cases from other hospitals. It has a neonatology unit with intensive care unit.

All case records of patients who had rupture of the uterus were retrieved and analyzed for maternal demographic characteristics, maternal and neonatal outcome and modes of treatment. In the same period of time (1981-1993) there were 168,395 deliveries without rupture of the gravid uterus. Details of these cases were obtained from the year books of the Maternity Hospital, Kuwait. Ruptured uterus was defined as the complete separation of the wall of the pregnant uterus with or without expulsion of the fetus [7].

\section{Statistical Methods}

Statistical package for social sciences (SPSS) was used to analyze the data; $\mathrm{z}$ test of proportions was used to compare two proportions. Chi-square test was used to study the association between two discrete variables and the Fisher exact test was used when the frequency in any cell was $\leq 5$. To compare means, Student's t test was used. Mann-Whitney U test was used to compare the medians of two groups. Chi-square for linear trend was used to study the trend of cesarean section rate from 1981 to 1993.

\section{Results}

\section{Incidence}

During the period 1981-1993 there were 168,486 deliveries with 91 cases of uterine rupture, giving an incidence of 1 in 1,851 . The declining incidence of uterine rupture in the Maternity Hospital, Kuwait from 1986 is shown in figure 1.

\section{Risk Factors}

Comparison of risk factors among mothers with or without ruptured uterus in all the deliveries in the study period is shown in table 1 . The percentage of cases with higher maternal age, grand multiparity, history of previous cesarean section, instrumental delivery, malpresentation, and use of oxytocics was significantly higher in mothers with uterine rupture than mothers without uterine rupture 


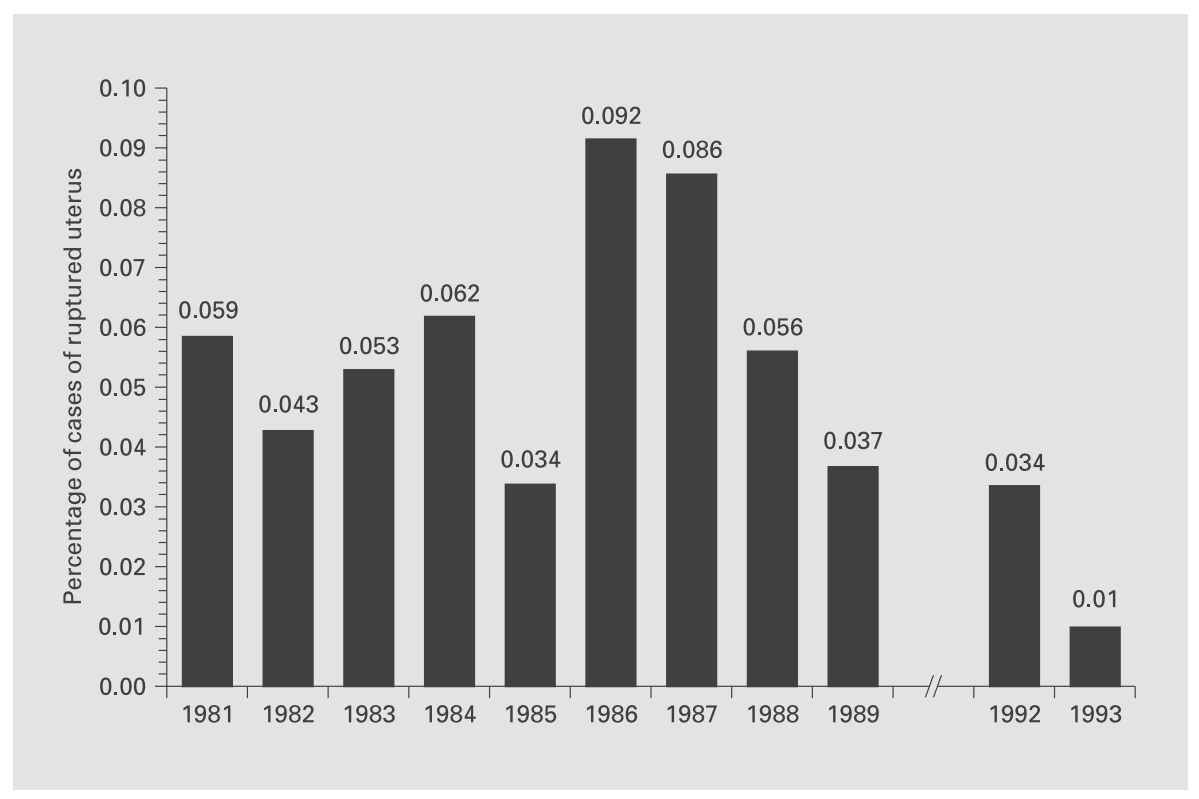

Fig. 1. Percentage of cases of uterine rupture during the period 1981-1993.

Table 1. Comparison of risk factors in mothers with or without uterine rupture

\begin{tabular}{|c|c|c|c|c|}
\hline & $\begin{array}{l}\text { Ruptured uterus } \\
(\mathrm{n}=91)\end{array}$ & $\begin{array}{l}\text { No rupture } \\
(\mathrm{n}=168,359)\end{array}$ & $\mathrm{p}$ value & $\begin{array}{l}\text { Odds } \\
\text { ratio }\end{array}$ \\
\hline Age $>35$ & $16(17.6)$ & $5,941 / 57,745(10.3)^{\mathrm{a}}$ & $<0.05$ & 1.86 \\
\hline Parity $<5$ & $43(47.3)$ & $23,577 / 144,412(16.3)^{b}$ & $<0.0001$ & 4.59 \\
\hline Previous cesarean section & $45(49.5)$ & $8,652 / 102,202 \quad(8.5)^{c}$ & $<0.0001$ & 10.58 \\
\hline Instrumentation & $19(20.9)$ & 13,139 & $<0.0001$ & 3.12 \\
\hline Malpresentation & $13(14.3)$ & $8,694 / 159,654 \quad(5.4)^{d}$ & $<0.001$ & 2.81 \\
\hline Use of oxytocics & $21(23.1)$ & 6,365 & $<0.0001$ & 7.64 \\
\hline Multiple pregnancy & $3(3.3)$ & 2,024 & $<0.06$ & 2.80 \\
\hline Maternal mortality & $3(3.3)$ & $20 \quad(0.01)$ & $<0.0001$ & 287 \\
\hline Perinatal mortality & $24 / 94(25.5)$ & $3,559 / 169,109$ & $<0.0001$ & 15.95 \\
\hline
\end{tabular}

Percentage is given in parentheses; $\mathrm{p}$ value by $\mathrm{z}$ test of proportion.

a Data for the years 1981-1986 and 1992 missing.

b Data for the years 1981 and 1992 missing.

c Data for the years 1981-1984 missing.

d Data for 1992 missing. 
Table 2. Risk factors contributing to uterine rupture based on presence or absence of a previous uterine scar

\begin{tabular}{lcccc}
\hline Risk factor & Cases & $\begin{array}{l}\text { Scarred } \\
\text { uterus } \\
(\mathrm{n}=51)\end{array}$ & $\begin{array}{l}\text { Unscarred } \\
\text { uterus } \\
(\mathrm{n}=40)\end{array}$ & *p value \\
\hline Parity $>5$ & 43 & $16(31.4)$ & $27(67.5)$ & $<0.01$ \\
Instrumental delivery & 19 & $7(13.7)$ & $12(30)$ & $\mathrm{NS}$ \\
Malpresentation & 13 & $4(7.8)$ & $9(22.5)$ & $\mathrm{NS}$ \\
Use of oxytocics & 21 & $5(9.8)$ & $16(40)$ & $<0.01$ \\
Multiple pregnancy & 3 & 0 & $3(7.5)$ & $\mathrm{NS}$ \\
\hline
\end{tabular}

Percentage is given in parentheses; *p value by chi-square test or Fisher exact test.

$(\mathrm{p}<0.05, \mathrm{p}<0.0001, \mathrm{p}<0.0001, \mathrm{p}<0.0001$, $\mathrm{p}<0.001$ and $\mathrm{p}<0.0001$, respectively).

Previous scar was present in 51 cases (56\%). Among these cases 42 had previously 1 or 2 cesarean sections, 3 had 3 or more cesarean sections, 3 had hysterotomies and the remaining 3 had myomectomies.

The risk factors contributing to uterine rupture based on a previously scarred or unscarred uterus are listed in table 2. In many patients more than one risk factor was present. Instrumental delivery (vacuum extraction/forceps delivery), malpresentation, and multiple pregnancy were present in 20.9, 4.3 and $3.3 \%$ of the cases, respectively. The total number of instrumental deliveries during the study period was 13,158 of which 19 cases were associated with ruptured uterus giving a percentage of $0.14 \%$. The percentage of use of oxytocics was significantly higher in patients with no previous uterine scar $(\mathrm{p}<0.01)$. Labor was induced by prostaglandins in 12 cases and by oxytocin in 3 cases. Augmentation of labor was carried out in 12 cases by oxytocin.

Parity of the patients ranged between 1 and 12 as shown in table 3 . The group of patients without previous uterine surgery had a median parity of $6($ mean $=5.88 \pm 2.53)$, which was significantly higher than the group of patients with a previous uterine surgery with a median of 3 (mean $=3.92 \pm 2.42 ; \mathrm{p}<$ $0.0001)$. Parity of 7 or more was present in $40 \%$ of the cases with no previous uterine scar and $11.8 \%$ of cases with a previous scar.

Incidence of uterine rupture in different age-groups is shown in table 3 . The peak age incidence was in the age-group 26-35 years (62.8\% of cases). Mean maternal age of patients (32.05 \pm 5.33 years) with previously unscarred uterus was significantly higher than the mean maternal age of patients with previously scarred uterus $(29.27 \pm 5.73$ years; $\mathrm{p}<0.05)$. Peak uterine rupture occurred at 40 weeks of gestational age ( $47 \%$ of cases), with a mean gestational age of $39.04 \pm 2.43$ weeks.

The site of uterine rupture is shown in table 4. In $84.4 \%$ of cases who previously had a lower segment cesarean section, the site of rupture was lower segment-anterior. Even in the unscarred uterus $50 \%$ of the cases had lower segment-anterior rupture.

The duration of labor in hours is higher in the previously unscarred uterus group (median $=5$; mean $\pm \mathrm{SD}=5.79 \pm 4.7)$ than scarred uterus group $($ median $=4$; mean $\pm \mathrm{SD}=$ 
Table 3. Uterine rupture according to maternal age and parity

\begin{tabular}{cccc}
\hline & $\begin{array}{l}\text { Scarred } \\
\text { uterus } \\
(\mathrm{n}=51)\end{array}$ & $\begin{array}{l}\text { Unscarred } \\
\text { uterus } \\
(\mathrm{n}=40)\end{array}$ & Total \\
& $\mathrm{n}=91)$ \\
\hline $\begin{array}{c}\text { Parity } \\
1\end{array}$ & $2(3.92)$ & $2(5)$ & $4(4.4)$ \\
2 & $19(37.3)$ & 0 & $19(20.9)$ \\
3 & $5(9.8)$ & $5(12.5)$ & $10(11)$ \\
4 & $9(17.6)$ & $6(15)$ & $15(16.5)$ \\
5 & $5(9.8)$ & $6(15)$ & $11(12.1)$ \\
6 & $5(9.8)$ & $5(12.5)$ & $10(11)$ \\
7 or more & $6(11.8)$ & $16(40)$ & $22(24.2)$ \\
Mean \pm SD & $3.92 \pm 2.42$ & $5.88 \pm 2.53$ & $4.78 \pm 2.64$ \\
Median & 3 & 6 & 4 \\
\hline Maternal age & & & \\
$\leq 20$ & $2(3.9)$ & 0 & $2(2.2)$ \\
$21-25$ & $11(21.6)$ & $5(12.5)$ & $16(17.6)$ \\
$26-30$ & $19(37.3)$ & $12(30)$ & $31(34.1)$ \\
$31-35$ & $12(23.5)$ & $14(35)$ & $26(28.6)$ \\
$36-40$ & $4(7.8)$ & $5(12.5)$ & $9(9.9)$ \\
$\geq 41$ & $3(5.9)$ & $4(10)$ & $7(7.7)$ \\
Mean $\pm \mathrm{SD}^{\mathrm{b}}$ & $29.27 \pm 5.73$ & $32.05 \pm 5.33$ & $30.49 \pm 5.7$ \\
& & &
\end{tabular}

Percentage is given in parentheses.

a Scarred uterus vs. unscarred uterus $(\mathrm{p}<0.0001$, by Mann-Whitney U test).

b Scarred uterus vs. unscarred uterus ( $\mathrm{p}<0.05$, by $\mathrm{t}$ test).
$5.04 \pm 4.12$ ). Similarly the hospital stay in days is higher in the previously unscarred uterus group (median $=10$; mean $\pm \mathrm{SD}=$ $10.9 \pm 3.26$ ) than scarred uterus group (median $=9$; mean $\pm \mathrm{SD}=9.84 \pm 3.95$ ). However these differences were not statistically significant (Mann-Whitney U test).

\section{Treatment}

The type of treatment administered is summarized in table 4 . The percentage of patients with simple repair of the uterus was significantly higher in the previously scarred uterus group (90.2\%) when compared to the previously unscarred uterus group $(57.5 \%$, $\mathrm{p}<0.001)$. Hysterectomy was performed in $25 \%$ of the patients with previously unscarred uterus, which was significantly higher than the $9.8 \%$ in patients with previously scarred uterus $(\mathrm{p}<0.01)$.

\section{Maternal and Neonatal Outcome}

Maternal and perinatal mortality was significantly higher in mothers with uterine rupture than mothers without uterine rupture (table 1). There were 3 maternal deaths, all of which occurred in the patients with previously unscarred uterus. The cause of death was hemorrhagic shock in 2 patients, while 1 of them died of pulmonary embolism. Out of the 94 infants (3 twins pregnancies), 70 infants were born alive and 24 either dead or died soon after birth. Approximately $66.6 \%$ of the total perinatal deaths were in the patients 
Table 4. Site of uterine rupture and type of treatment in the previously scarred and unscarred uterus

\begin{tabular}{|c|c|c|c|c|c|}
\hline & $\begin{array}{l}\text { LSCS } \\
(\mathrm{n}=45)\end{array}$ & $\begin{array}{l}\text { Myomectomy } \\
(\mathrm{n}=3)\end{array}$ & $\begin{array}{l}\text { Hysterotomy } \\
(\mathrm{n}=3)\end{array}$ & $\begin{array}{l}\text { Unscarred } \\
\text { uterus } \\
(\mathrm{n}=40)\end{array}$ & $\begin{array}{l}\text { Total } \\
(\mathrm{n}=91)\end{array}$ \\
\hline \multicolumn{6}{|l|}{ Site of rupture } \\
\hline Fundoanterior & $4 \quad(8.9)$ & $2(66.7)$ & $1(33.3)$ & $4(10)$ & $11(12.1)$ \\
\hline Lower segment-anterior & $38(84.4)$ & $1(33.3)$ & 0 & $20(50)$ & $59(64.8)$ \\
\hline Fundoposterior & 0 & 0 & 0 & $1(2.5)$ & $1(1.1)$ \\
\hline Lower segment-posterior & 0 & 0 & $1(33.3)$ & $5(12.5)$ & $6(6.6)$ \\
\hline Anterolateral & $2(4.4)$ & 0 & $1(33.3)$ & $9(22.5)$ & $12(13.2)$ \\
\hline Posterolateral & 0 & 0 & 0 & $1 \quad(2.5)$ & $1(1.1)$ \\
\hline Lateral & $1(2.2)$ & 0 & 0 & 0 & $1(1.1)$ \\
\hline \multicolumn{6}{|l|}{ Type of treatment } \\
\hline Repair & $40(88.9)$ & $3(100)$ & $2(67.7)$ & $23(57.5)$ & $68(74.7)$ \\
\hline Repair and tubal ligation & $3(6.7)$ & 0 & $1(33.3)$ & $7(17.5)$ & $8(8.8)$ \\
\hline Subtotal hysterectomy & $1(2.2)$ & 0 & 0 & $2(5)$ & $6(6.6)$ \\
\hline Total hysterectomy & $1 \quad(2.2)$ & 0 & 0 & $8(20)$ & $9(9.9)$ \\
\hline
\end{tabular}

Percentage is given in parentheses. LSCS = Lower segment cesarean section.

with previously unscarred uterus. The perinatal mortality rate was 157 per 1,000 in the scarred uterus group, which is significantly lower than the perinatal mortality $(372$ per $1,000)$ in the unscarred uterus group $(\mathrm{p}<0.05$ by chi-square). Mean birth weight (in kilograms) of babies who were born alive and well was $3.47 \pm 0.59$, whereas the mean birth weight of babies who were born dead or died soon after birth was $3.36 \pm 1.06$. Total perinatal mortality was 255 per 1,000 , which is significantly higher than the mean perinatal mortality rate over the same period of the study in the Maternity Hospital of Kuwait of 21 per $1,000(\mathrm{p}<0.0001)$.

\section{Discussion}

Uterine rupture continues to be one of the great obstetric emergencies associated with high maternal and neonatal mortality and morbidity [4, 6, 8-11]. The incidence of uterine rupture varies widely, ranging from 1:97 in Turkey [5] to $1: 6,637$ in the USA [6] depending on the type of obstetric care and population study. The incidence of uterine rupture in different countries is shown in table 5. Inaccessibility to health information, lack of transportation, poor access to health services, inadequate family planning services and inexperienced birth attendants are the major problems associated with high incidence of uterine rupture in the rural areas of developing countries. The incidence of uterine rupture of $1: 1,851$ in this study is lower than that of the other developing countries [5, $12,13]$, but is higher than that in the developed countries $[6,14,15]$. However, the statistics of the years 1992-1993 (fig. 1) showed an incidence comparable to that in developed countries. Kuwait provides an efficient antenatal care service and referral network for its obstetric population. The Maternity Hospital, 
Table 5. Incidence of uterine rupture in different countries

\begin{tabular}{|c|c|c|c|c|c|c|}
\hline Reference (country) & Period & Deliveries & Ruptures & Incidence & $\begin{array}{l}\text { Perinatal } \\
\text { mortality }\end{array}$ & $\begin{array}{l}\text { Maternal } \\
\text { mortality }\end{array}$ \\
\hline Present study (Kuwait) & $1981-1993$ & 168,486 & 91 & $1: 1,851$ & 25.5 & 3.3 \\
\hline Rachagan et al. [16] (Malaysia) & 1968-1989 & 100,860 & 34 & $1: 2,966$ & 32.4 & 0 \\
\hline Kafkas and Taner [5] (Turkey) & $1983-1988$ & 3,962 & 41 & $1: 97$ & 82.9 & 7.3 \\
\hline Deneke [12] (Ethiopia) & 1983-1988 & 22,225 & 127 & $1: 175$ & 100 & 11 \\
\hline Lynch and Pardy [25] (Australia) & $1988-1992$ & 31,115 & 27 & $1: 1,152$ & 18.5 & 0 \\
\hline Chen et al. [15] (Singapore) & 1983-1992 & 164,606 & 26 & $1: 6,331$ & 3.8 & 7.4 \\
\hline Gardeil et al. [14] (Ireland) & 1982-1991 & 65,488 & 15 & $1: 4,366$ & 33 & 0 \\
\hline Spaulding and Gallup [6] (USA) & $1956-1978$ & 100,000 & 15 & $1: 6,667$ & 13.3 & 0 \\
\hline Elkady et al. [13] (Egypt) & $1979-1988$ & 46,207 & 126 & $1: 367$ & 73.2 & 21.4 \\
\hline \multicolumn{7}{|l|}{ Van der Merve and Ombelet [23] } \\
\hline (South Africa) & $1968-1982$ & 77,133 & 89 & $1: 866$ & 52.8 & 5.6 \\
\hline Adams et al. [26] (USA) & $1963-1983$ & 35,252 & 24 & $1: 1,469$ & 45.8 & 4.2 \\
\hline
\end{tabular}

Kuwait is well equipped with modern technology and has experienced staff. However, it is suggested that there is a need to focus more on provision of adequate family planning services to discourage grand multiparity in $\mathrm{Ku}-$ wait.

Rupture of the uterus may occur either in a previously scarred uterus or an unscarred one. Various reports have shown that scarred uterus is a major predisposing factor for uterine rupture $[8,10,16]$. The risk of uterine rupture in a previously scarred uterus is increased by a factor of 8-30 as shown in the different studies [3, 4]. In this study this risk is 6-fold, a factor that is slightly smaller than those reported in other studies. Cesarean section, the most common cause of a scarred uterus, accounted for $88.2 \%$ of the cases. Scars due to hysterotomy and myomectomy rarely result in uterine rupture [17]. In a review report involving 231 cases of uterine rupture from 11 studies, only 2 cases were due to previous scar from myomectomy [17]. In the present series, 3 cases, 1 of hysterotomy and 2 of myomectomy, were responsible for a previous scar.

Ruptured Uterus
Studies have shown the incidence of uterine rupture with an intact uterus to be as low as $0.014 \%$, that is comparable to $0.025 \%$ in this study. In this study, multiparity and higher maternal age were predisposing factors to the rupture of a previously intact uterus. Higher maternal age is one of the predisposing factors because of its association with increased parity. Grandmultipara is a dangerous patient because it gives a false sense of security arising from the many previous uncomplicated vaginal deliveries. There have been several studies which show mean parity at the time of uterine rupture to be between 5 and $6[1,3,18]$. Successive pregnancies do not increase the risk of uterine rupture due to an increased proportion of fibrous tissue in the uterine wall, but in multipara, obstruction stimulates violent uterine action with danger of uterine rupture [16]. In this study $67.5 \%$ of the patients with previously unscarred uterus had a parity of 5 or more. The percentage of cases with instrumental deliveries, malpresentations and multiple pregnancies was higher in patients with unscarred uterus than scarred uterus, but not statistically significant.

Med Principles Pract 2000;9:97-105 
The incidence of oxytocin use among patients with a uterine rupture ranges from 13 to $46 \%$ [19]. There is a controversy in use of oxytocin in previously scarred uterus. According to some investigators [7] it should be contraindicated, whereas others suggest that if used in a judicious manner, there is no increased risk of uterine rupture [20]. Prostaglandin $\left(\mathrm{PGE}_{2}\right)$ is a potent oxytocic and rupture of the unscarred uterus has been reported $[21,22]$. In this study the percentage of use of these oxytocics was significantly higher in patients with no previous scar, which may reflect the fear of using them in patients with a previous uterine scar.

Instrumentation may lead to traumatic rupture of the uterus. Vacuum extraction was used more commonly in this study. It was used in 7 cases with a previous uterine scar and 12 cases of an intact uterus. Studies have shown that there is a danger of uterine rupture when the vacuum extractor is applied in women with an unengaged head, a large fetus, an incompletely dilated cervix and pelvis of questionable capacity. Presently, malpresentations are detected reliably by ultrasound. Prolonged labor and difficult vaginal deliveries have been replaced by cesarean section. As a result, obstetric trauma is less common and rupture of an unscarred uterus has become relatively rare.

After a scar due to previous cesarean section, the rupture is usually a transverse rupture of the lower uterine segment, which gives few symptoms, less bleeding and which is easy to repair [2,3]. In this study, patients who previously underwent cesarean section, $84.4 \%$ had a lower segment-anterior rupture (table 5). Rupture of the intact uterus is usually irregular and extensive, which necessitates more blood transfusions, hysterectomies and longer postoperative stay in the hospital [13, 23]. It was also observed that $20 \%$ of the cases with previously unscarred uterus underwent total hysterectomies as compared to $1.9 \%$ of cases in the previously scarred group. Similarly more blood transfusions and longer postoperative stay in the hospital were observed in the unscarred group as compared to the scarred group, but the difference was not statistically significant.

Although total abdominal hysterectomy is considered to be the procedure of choice [8, $13,15]$ unless cardiovascular decompensation necessitates subtotal hysterectomy or simple repair, only 9 cases underwent this procedure in this study. Seventy-six cases $(83.5 \%)$ with uterine rupture were treated by suture repair (68 cases without and 8 with tubal ligation). Repair of uterine rupture is a less aggressive approach when compared to hysterectomy and is associated with lower maternal morbidity [16]. It should be pointed out that in Kuwait, preservation of fertility and continuation of menstruation play an important role in the psychology of the obstetric population. The objection against repair of the uterus without tubal ligation is the possibility of recurrence of uterine rupture, which is estimated to be $4.3-19 \%$ [24]. Therefore when suture repair is undertaken without tubal ligation, the patient should be informed and future delivery should be well planned.

\section{Conclusion}

The low maternal (3.3\%) and fetal (25.5\%) mortality in our series compared to other developing countries (table 5) was due to the fact that in all but 1 case, the uterine rupture occurred in the hospital. Adequate preoperative resuscitation, early diagnosis, improved techniques and experienced surgeons in our hospital were the determinants of maternal and fetal survival. Our perinatal and maternal mortality is also comparable to that of developed countries. 


\section{References}

1 Beacham WD, Beacham DW, Webster HD, Fielding SL: Rupture of the uterus as New Orleans Charity Hospital. Am J Obstet Gynecol 1970;106:1083-1087.

2 Fedorkow DM, Nimrod CA, Taylor PJ: Ruptures uterus in pregnancy: A Canadian hospital's experience. Can Med Assoc J 1997;137:27-29.

3 Marguilies D, Crapanzano JT: Rupture of the intact uterus. Obstet Gynecol 1966;27:863-868.

4 Lao TT, Leung BFH: Rupture of the gravid uterus. Eur J Obstet Gynecol Reprod Biol 1987;25:175-180.

5 Kafkas S, Taner CE: Ruptured uterus. Int J Gynecol Obstet 1990;34: 41-44.

6 Spaulding LB, Gallup DG: Current concepts of management of rupture of the gravid uterus. Obstet Gynecol 1979;54:437-441.

7 Plauche W, VonAlmen W, Muller $\mathrm{R}$ : Catastrophic uterine rupture. Obstet Gynecol 1984;64:792-797.

8 Eden RD, Parker RT, Gall SG: Rupture of the pregnant uterus: A 53 year review. Obstet Gynecol 1986; 68:671-674.

9 Nielsen TF, Ljungblad U, Hagbarg $\mathrm{H}$ : Rupture and dehiscence of cesarean section scar during pregnancy and delivery. Am J Obstet Gynecol 1989;160:569-573.
10 Chazotte C, Cohen WR: Catastrophic complications of previous cesarean section. Am J Obstet Gynecol 1990;163:738-742.

11 Megafu U: Factors influencing maternal survival in ruptured uterus. Int J Gynecol Obstet 1985;23:475480.

12 Deneke F: Ruptured uterus in Ethiopia. Int J Gynecol Obstet 1996;54:175-176.

13 Elkady AA, Bayomy HM, Bekhie MT, Nagib HS, Wahba AKA: Review of 120 cases of ruptured gravid uterus. Int Surg 1993;87:231-235.

14 Gardeil F, Daly S, Turner MG: Uterine rupture in pregnancy reviewed. Eur J Obstet Gynecol Reprod Biol 1994;56:107-110.

15 Chen LH, Tan KH, Yeo GS: A ten year review of uterine rupture in modern practice. Ann Acad Med Singapore 1995;24:830-835.

16 Rachagan SP, Raman S, Balasundram G, Balakrishnan S: Rupture of the pregnant uterus: A 21 year review. Aust NZ J Obstet Gynaecol 1991;31:1:37-40.

17 Levi AA: Rupture of the pregnant uterus: Relationship to previous myomectomy. Obstet Gynecol 1961;18:223-229.

18 Yussman MA, Haynes DM: Rupture of the gravid uterus. Obstet Gynecol 1970;36:115.
19 Phelan JP: Uterine rupture. Clin Obstet Gynecol 1990;33:432-437.

20 Phelan JP: Vaginal birth after multiple prior cesareans; in Phelam JP, Clark SL (eds): Cesarean Delivery. New York, Elsevier, 1988, p 491.

21 Sawyer MM, Lipshitz J, Anderson GD, Dilts PV Jr: Third trimester uterine rupture associated with vaginal prostaglandin E2. Am J Obstet Gynecol 1981;140:710-711.

22 Azem F, Jaffa A, Lessing JB, Peyser MR: Uterine rupture with the use of a low-dose vaginal PGE2 tablet. Acta Obstet Gynecol Scand 1993; 72:316-317.

23 Van der Merwe JV, Ombelet WUAM: Rupture of the uterus: A changing picture. Arch Gynecol 1987;240:159-171.

24 Seth SS: Results of treatment of rupture of the uterus by suturing. J Obstet Gynaecol Br Commonw 1968; 75:55-68.

25 Lynch JC, Pardy JP: Uterine rupture and scar dehiscence: A five year survey. Anaesth Intensive Care 1996;24:699-704.

26 Adams DM, Druzin ML, Cederqvist LL: Intrapartum uterine rupture. Obstet Gynecol 1989;73:471473 